\title{
THE VARIATION IN STRENGTH OF THE HUMAN BLOOD GROUP $P$
}

\author{
SIR RONALD FISHER \\ Department of Genetics, Combridge
}

Received 4.xii.52

\section{INTRODUCTION}

Soon after their discovery (I) of the blood group known by the genetical symbols $P, p$, Landsteiner and Levine called attention to the great variability of the $P$ reaction with anti- $P$ sera. This variability has proved very troublesome, and for some years the validity of estimates of gene frequencies was in some doubt, owing to the possibility that an unknown proportion of weak positive reactions were passing as negative. Moreover, there is still no anti-p reagent to supplement the typing antibody first discovered.

Owing to the improved technique developed by Jonsson and Henningsen (2), and the use of potent testing fluids, the difficulty of distinguishing weakly reacting blood containing $P$ from the recessive form $p p$ is now believed to be overcome. The causes of variation in strength are, however, still obscure. Henningsen has indeed suggested (3) that his data may be interpreted as showing a series of four alleles :-

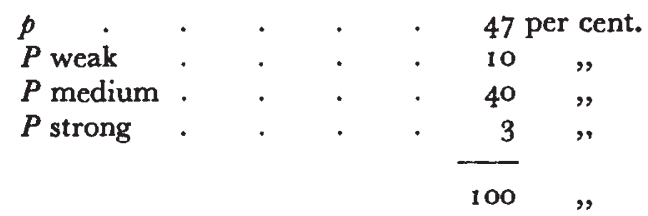

After examining the data on which this suggestion was based, I suggested in correspondence that a more detailed examination of this fine body of material might be profitable. Dr Henningsen, therefore, very cordially sent me further details, and some additional observations, together with information as to factors such as age of the donor, freshness of the sample, etc., which have guided me in the choice of the further calculations I have made. Especially because my conclusions diverge somewhat from those to which Henningsen was first led, I should like to make it clear that my enquiry rests exclusively on his work, and has been made possible only by his courtesy.

\section{THE FAMILY DATA}

In the case of 221 families both parents were classified in four phenotypic classes as Strong, Medium, Weak and Negative. As the frequency distribution for children differed considerably from that 
for the parents, I have felt on safe ground in recognising for these only the distinction of Positive and Negative. This distinction is sufficient to allow of an estimation of limited but useful precision of the proportion of each phenotypic class of parent who are heterozygous, meaning by this that they contain the negative gene $p$, whatever allelomorph it may be combined with.

For this purpose we need to know for each of the nine phenotypic classes of mating, which might show segregation among the children : (i) How many matings have yielded at least one negative child, (ii) in the case of matings with no negative child, how many children have been tested. The number of children in families of the first class is a matter of indifference, since any one negative child proves both parents to be heterozygous, if not known to be themselves negative, and further information can tell us no more than this. In the cases of families with no negative children on the contrary, the larger the family the higher is the probability that at least one parent is homozygous.

With these considerations in view, the whole of the data may be summarised compactly as in table $\mathrm{I}$.

TABLE I

\begin{tabular}{|c|c|c|c|c|}
\hline Type of mating & $\begin{array}{l}\text { Numbers of } \\
\text { matings with } \\
\text { negative } \\
\text { children }\end{array}$ & $\begin{array}{l}\text { Numbers of tested } \\
\text { children in } \\
\text { matings with no } \\
\text { negative children }\end{array}$ & $\begin{array}{c}\text { Numbers of } \\
\text { matings with } \\
\text { no negative } \\
\text { children }\end{array}$ & $\begin{array}{c}\text { Total } \\
\text { numbers of } \\
\text { matings }\end{array}$ \\
\hline $\begin{array}{l}\text { Strong-Strong . } \\
\text { Strong-Medium } \\
\text { Strong-Weak. } \\
\text { Strong-Negative } \\
\text { Medium-Medium } \\
\text { Medium-Weak } \\
\text { Medium-Negative } \\
\text { Weak-Weak. } \\
\text { Weak-Negative } \\
\text { Negative-Negative }\end{array}$ & $\begin{array}{r}3 \\
2 \\
0 \\
5 \\
16 \\
6 \\
23 \\
1 \\
8 \\
13\end{array}$ & 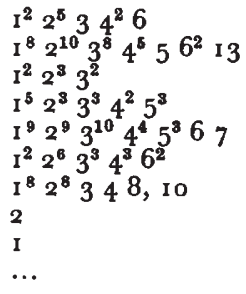 & $\begin{array}{r}\text { I I } \\
35 \\
7 \\
16 \\
37 \\
16 \\
20 \\
1 \\
1 \\
0\end{array}$ & $\begin{array}{r}14 \\
37 \\
7 \\
21 \\
53 \\
22 \\
43 \\
2 \\
9 \\
13\end{array}$ \\
\hline Total & 77 & $\cdots$ & I 44 & 221 \\
\hline
\end{tabular}

Of the total $44^{2}$ parents tested 99 were negative. The proportion of recessive genes is estimated to be

$$
\sqrt{99 / 44^{2}}=47 \cdot 3267 \text { per cent. }
$$

Consequently, the frequency of positive genes of all possible sorts is 52.6733 per cent., and the proportion of persons with two such genes, who may be called homozygous positives, is

$$
(52.6733 \text { per cent. })^{2}=27 \cdot 745 \text { per cent. }
$$

We may, therefore, using the proportion of negative parents only, estimate the number of homozygous positives to be

$$
442 \times 27 \cdot 745 \text { per cent. }=122 \cdot 6 .
$$


These must be distributed in some way among the 93 strong, 208 medium and 42 weak recorded. If estimates of the numbers of homozygotes in each of these classes give a concordant estimated total, without using the number of parents negative, this will be a genuine confirmation of the consistency of the data, and of the appropriateness of the method of interpretation.

\section{THEORY OF THE CALCULATIONS}

If the probability of each child being positive is $3 / 4$, the probability that none will be negative out of $s$ is $(3 / 4)^{s}$, and the probability of one at least being negative is

$$
u_{s}=\mathrm{I}-(3 / 4)^{s} \text {. }
$$

Similarly, if, as in a backcross, the probability for each child is $1 / 2$, the probability of at least one negative child is

$$
v_{s}=\mathrm{I}-(\mathrm{I} / 2)^{s} \text {. }
$$

These auxiliary quantities, so far as they are needed for the actual family sizes recorded are shown in table 2 .

TABLE 2

\begin{tabular}{|c|c|c|c|}
\hline $\begin{array}{l}\text { Size of } \\
\text { family }\end{array}$ & $\begin{array}{c}u_{s} \\
1-(3 / 4)^{s}\end{array}$ & $\begin{array}{l}\text { Size of } \\
\text { family }\end{array}$ & $\begin{array}{c}v_{8} \\
1-(1 / 2)\end{array}$ \\
\hline $\begin{array}{r}1 \\
2 \\
3 \\
4 \\
5 \\
6 \\
7 \\
13\end{array}$ & $\begin{array}{l}0.25 \\
0.4375 \\
0.578125 \\
0.683594 \\
0.762695 \\
0.822021 \\
0.869680 \\
0.976243\end{array}$ & $\begin{array}{r}1 \\
2 \\
3 \\
4 \\
5 \\
8 \\
10\end{array}$ & $\begin{array}{l}o \cdot 5 \\
o \cdot 75 \\
0 \cdot 875 \\
o \cdot 9375 \\
o \cdot 96875 \\
o \cdot 996094 \\
0 \cdot 999024\end{array}$ \\
\hline
\end{tabular}

Values of $\mathrm{u}_{\mathrm{s}}$ and $\mathrm{v}_{\mathrm{s}}$ for various sizes of family

If $p_{1}$ is the proportion of heterozygotes among individuals classified as Strong, $p_{2}$ the proportion among the Medium, and $p_{3}$ among the Weak, the proportion of the various mating types capable of giving Negative children can be easily calculated. E.g. in the mating type Strong mated to Strong, the proportion of matings in which both parents are heterozygous will be

$$
p_{1}^{2}
$$

and the probability of a family of $s$ having at least one Negative child will be

$$
p_{1}{ }^{2} u_{s}
$$

while the probability of such a family having no Negative child will be

$$
1-p_{1}^{2} u_{s}
$$


Efficient scores for families of $s$ children of these two kinds are found by taking the logarithms, and differentiating with respect to the unknown parameter $p_{1}$. Thus we have

Score for family with at least one Negative child $2 / p_{1}$

Score for family with no Negative child $\frac{-2 p_{1} u_{s}}{\left(\mathrm{I}-p_{1}{ }^{2} u_{s}\right)}$

In connection with these scores we shall also be concerned to evaluate the amount of information concerning $p_{1}$ supplied by the family in question, and this may be evaluated from the differential coefficient of the score with respect to $p_{1}$, taken with reversed sign.

So, for a family of $s$ children from a mating with both parents Strong, we have

From a family with at least one Negative child, information

$$
2 / p_{1}^{2}=S / p_{1}
$$

From a family with no Negative child $-\mathrm{S} / p_{1}+\mathrm{S}^{2}$.

For a mating of Strong and Medium parents, we have correspondingly the probability

$$
p_{1} p_{2} u_{s}
$$

of at least one Negative child, and

$$
I-p_{1} p_{2} u_{s}
$$

of no Negative child. Such families are to be scored both for $p_{1}$ and for $p_{2}$, the scores being

Negative child

$$
\text { For } p_{1}
$$

For $p_{2}$

No Negative child

$$
\begin{array}{cc}
\mathrm{I} / p_{1} & \mathrm{I} / p_{2} \\
-p_{2} u_{s} /\left(\mathrm{I}-p_{1} p_{2} u_{s}\right) & -p_{1} u_{s} /\left(\mathrm{I}-p_{1} p_{2} u_{s}\right)
\end{array}
$$

From these again the amounts of information are $S_{1} / p_{1}$ and $S_{2} / p_{2}$ for families with a Negative child, while in the alternative case they are

$$
\mathrm{S}_{1}^{2}, \quad \mathrm{~S}_{1} \mathrm{~S}_{2}, \quad \mathrm{~S}_{2}{ }^{2}
$$

the middle term being the cross information for the simultaneous estimation of $p_{1}$ and $p_{2}$.

A third case is offered by the mating Strong with Negative. Here the probabilities are

$\begin{array}{llll} & p_{1} v_{s} & \text { and } & \mathrm{I}-p_{1} v_{s} \\ \text { with scores } & \mathrm{I} / p_{1} & \text { and } & v_{s} /\left(\mathrm{I}-p_{1} v_{s}\right)\end{array}$

and amounts of information

respectively.

$$
\mathrm{S} / p_{1} \quad \text { and } \quad \mathrm{S}^{2}
$$

Since, on the whole, parents classified as Weak produce Negative children more rather than less frequently than would be expected if 
all were heterozygous, we shall simplify the calculations by taking $p_{3}=1$. In this case the matings Strong by Weak and Medium by Weak will be scored just as are Strong by Negative and Medium by Negative, save that $u_{s}$ will now be used in place of $v_{s}$.

\section{THE ESTIMATION OF THE PROPORTIONS HOMOZYGOUS}

Table 3 gives in detail the scores and amounts of information credited to each class of family according to the type of mating involved. The trial values employed, $1 / 3$ for $p_{1}$, and 0.7 for $p_{2}$, were known to be very near the values of maximum likelihood. The total scores for $p_{1}$ and $p_{2}$ are found to be

$$
0.43^{8} 3 \text { and } 0.5286 \text {. }
$$

The totals for all families also gives the information matrix

$$
\left\{\begin{array}{rr}
\text { I } 58 \cdot 4093 & \text { I I } \cdot 9189 \\
\text { II } \cdot 9189 & 306 \cdot 3893
\end{array}\right\},
$$

so that adjustments $\delta p_{1}$ and $\delta p_{2}$ to the trial value may be calculated from the equations,

$$
\begin{aligned}
{ }_{1} 5^{8} \cdot 4093 \delta p_{1}+\text { I I } \cdot 9189 \delta p_{2} & =0.4383 \\
\text { I I } 9189 \delta p_{1}+306 \cdot 3893 \delta p_{2} & =0.5286 .
\end{aligned}
$$

The covariance matrix is found by inverting the information matrix, and multiplied by 10,000 this is

$$
\left\{\begin{array}{rr}
63 \cdot 3129 & -2 \cdot 4629 \\
-2 \cdot 4629 & 32 \cdot 7340
\end{array}\right\}
$$

giving the adjustments

$\delta p_{1} \quad 0 \cdot 264$ per cent., $\quad \delta p_{2} \quad 0 \cdot 162$ per cent.,

and the corrected estimates

$$
p_{1} \quad 33.597 \text { per cent., } \quad p_{2} \quad 70 \cdot 162 \text { per cent., }
$$

with standard errors

$$
\pm 7.957 \text { and } \pm 5.721 \text {. }
$$

We may now partition the 442 parents observed, both phenotypically and genotypically as follows :-

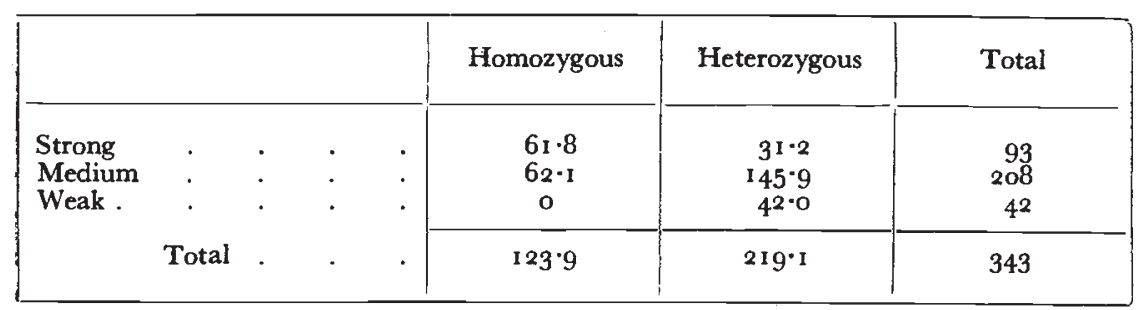

The agreement between the number of homozygotes estimated from the families without reference to negative parents, namely 
123.9, with 122.6 the number estimated from the number of negative parents without reference to the families, is quite striking.

TABLE 3

Scores for each class of family, $\mathrm{p}_{1}=0.3, \mathrm{p}_{2}=0.7$

(a) Scoring for $p_{1}$

\begin{tabular}{|c|c|c|c|c|c|c|c|c|c|}
\hline & & & & & & & Families & Score $p_{1}$ & $i_{p_{1} p_{1}}$ \\
\hline \multicolumn{10}{|c|}{ Strong mated to Strong } \\
\hline \multirow{3}{*}{\multicolumn{3}{|c|}{$\begin{array}{l}\text { With Negative children } \\
\text { Without }\left(\begin{array}{l}\text { I child } \\
2 \text { children }\end{array}\right.\end{array}$}} & - & . & . & . & 3 & $+18 \cdot 0000$ & $65 \cdot 63$ I 3 \\
\hline & & & • & . & . & . & 2 & $-0 \cdot 3429$ & $0 \cdot 0588$ \\
\hline & & & . & . & . & . & 5 & $-1 \cdot 5328$ & $0 \cdot 4699$ \\
\hline \multirow{4}{*}{$\begin{array}{l}\text { Negative } \\
\text { children }\end{array}$} & 3 &, & . & . & . & . & I & -0.4119 & $0 \cdot 1697$ \\
\hline & 4 & , & • & . & . & . & 2 & -0.9864 & $0 \cdot 4865$ \\
\hline & & , & • & . & . & . & I & $-0.603 I$ & $0 \cdot 3637$ \\
\hline & & & & & & & & $+14 \cdot 1229$ & $67 \cdot 1799$ \\
\hline \multicolumn{10}{|c|}{ Strong mated to Negative } \\
\hline \multirow{3}{*}{\multicolumn{3}{|c|}{$\begin{array}{l}\text { With Negative children } \\
\text { Without }\left(\begin{array}{l}\text { I child } \\
2 \text { children }\end{array}\right.\end{array}$}} & . & . & . & . & 5 & $+15 \cdot 0000$ & $45^{\circ} \cdot 0000$ \\
\hline & & & - & . & $\cdot$ & . & 5 & $-3 \cdot 0000$ & $I \cdot 8000$ \\
\hline & & & - & - & - & . & 3 & -3.0000 & $3^{\cdot 0000}$ \\
\hline \multirow{4}{*}{$\begin{array}{l}\text { Negative } \\
\text { children }\end{array}$} & 3 & , & • & · & . & $\cdot$ & 3 & $-3 \cdot 7059$ & $4 \cdot 5779$ \\
\hline & 4 & ", & - & - & . & - & 2 & $-2 \cdot 7273$ & 3.7191 \\
\hline & 5 & $"$ & $\cdot$ & • & $\cdot$ & $\cdot$ & 3 & $-4 \cdot 29^{2} 3$ & $6 \cdot 1413$ \\
\hline & & & & & & & & $-I \cdot 7255$ & $64 \cdot 23^{8} 3$ \\
\hline \multicolumn{10}{|c|}{ Strong mated to Weak } \\
\hline \multirow{3}{*}{\multicolumn{3}{|c|}{$\begin{array}{l}\text { With Negative children } \\
\text { Without }\left\{\begin{array}{l}1 \text { child } \\
\text { Negative } \\
2 \text { children }\end{array}\right.\end{array}$}} & 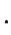 & . & . & . & o & $\ldots$ & $\ldots$ \\
\hline & & & . & . & . & . & 2 & -0.5455 & $0 \cdot 1488$ \\
\hline & & & . & . & . & . & 3 & $-\mathrm{I} \cdot 53^{66}$ & $0 \cdot 7^{8} 70$ \\
\hline \multirow[t]{2}{*}{ children } & 3 & , & • & · & • & $\cdot$ & 2 & $-I \cdot 4323$ & I $\cdot 0257$ \\
\hline & & & & & & & & $-3 \cdot 5^{1} 44$ & $I \cdot 96 ! 5$ \\
\hline \multicolumn{10}{|c|}{ Strong mated to Medium } \\
\hline \multirow{9}{*}{$\begin{array}{l}\text { Without } \\
\text { Negative } \\
\text { children }\end{array}$} & tive & hildren & . & - & . & . & 2 & $+6 \cdot 0000$ & I $8 \cdot 0000$ \\
\hline & & iild & - & . & - & . & 8 & $-\mathrm{I} \cdot 4867$ & 0.2763 \\
\hline & 20 & iildren & . & . & . & . & Io & $-3.4^{107}$ & $1 \cdot 1633$ \\
\hline & 3 & ," & . & . & - & . & 8 & $-3 \cdot 7423$ & $I \cdot 7506$ \\
\hline & 4 & ", & . & - & . & . & 5 & $-2 \cdot 8466$ & $1 \cdot 6206$ \\
\hline & 5 & , & . & . & . & . & I & -0.6495 & $0 \cdot 42$ I 9 \\
\hline & 6 & , & . & . & . & - & 2 & $-1 \cdot 4239$ & I 0137 \\
\hline & I 3 & ", & . & · & . & · & I & $-0.885^{\circ}$ & $0 \cdot 783^{2}$ \\
\hline & & & & & & & & $-8 \cdot 444$ & $25 \cdot 0296$ \\
\hline & & & & & & & & $\begin{array}{l}i p_{1} p_{2} \\
i_{p_{2} p_{3}} \\
\text { Score }\end{array}$ & $\begin{array}{r}11 \cdot 9189 \\
5 \cdot 6756 \\
-4 \cdot 0213\end{array}$ \\
\hline
\end{tabular}

\section{DISCUSSION}

It is clearly demonstrated in the foregoing sections that one important cause of variation in the strength of the $P$ reaction lies simply in the difference between persons with two and persons with only one positive gene. Other genetical causes are possible, but it is not easy, without family studies freed from the quantitative effects of age, even to prove their existence, still less to exhibit their nature. 
Strength of reaction is generally observed to be associated in parents and offspring. Nevertheless, the view that all causes other than homozygosity were exogenic could not be disproved without a quantitative study showing that the degree of association observed is really greater than that to be expected merely from the association of homozygosity in parents and children.

TABLE 3 (continued)

(b) Scoring for $p_{\mathrm{z}}$

\begin{tabular}{|c|c|c|c|c|c|c|c|c|c|}
\hline & & & & & & & Families & Score $p_{2}$ & $i_{p_{2} p_{2}}$ \\
\hline Strong mated th & o Med & lium & - & . & . & & $\cdots$ & $-4 \cdot 0213$ & $5 \cdot 675^{6}$ \\
\hline \multicolumn{10}{|c|}{ Medium mated to Medium } \\
\hline \multirow{2}{*}{\multicolumn{3}{|c|}{$\begin{array}{c}\text { With Negative children } \\
\text { (1 child. } \\
2 \text { children }\end{array}$}} & & . & . & . & 16 & $+45^{\circ} 7^{143}$ & $117 \cdot 9046$ \\
\hline & & & . & - & . & . & 9 & -3.5897 & $\begin{array}{l}1 \cdot 4318 \\
5.4705\end{array}$ \\
\hline \multirow{6}{*}{$\begin{array}{l}\text { Without } \\
\text { Negative } \\
\text { children }\end{array}$} & & , & . & . & . & : & $\begin{array}{r}9 \\
10\end{array}$ & $-11 \cdot 2928$ & $\begin{array}{r}3.4703 \\
12 \cdot 7527\end{array}$ \\
\hline & & $"$ & . & . & . & . & 4 & $-5 \cdot 75^{62}$ & $8 \cdot 2835$ \\
\hline & & ," & . & . & . & . & 3 & $-5 \cdot 114^{8}$ & $8 \cdot 7204$ \\
\hline & & ," & . & . & . & . & 1 & $-1 \cdot 9270$ & $3 \cdot 7133$ \\
\hline & 7 & , & · & - & - & $\cdot$ & 1 & $-2 \cdot 1217$ & $4 \cdot 5016$ \\
\hline & & & & & & & & $+8 \cdot 8954$ & $162 \cdot 7784$ \\
\hline \multicolumn{10}{|c|}{ Medium mated to Weak } \\
\hline \multirow{2}{*}{\multicolumn{3}{|c|}{$\begin{array}{l}\text { With Negative children } \\
\text { I child. }\end{array}$}} & . & . & & & 6 & $+8 \cdot 5714$ & $12 \cdot 2449$ \\
\hline & & & : & : & . & . & 6 & $-3 \cdot 7838$ & $2 \cdot 3862$ \\
\hline \multirow{4}{*}{$\begin{array}{l}\text { Without } \\
\text { Negative } \\
\text { children }\end{array}$} & 3 & ," & . & . & . & . & 3 & $-2 \cdot 9134$ & $2 \cdot 8293$ \\
\hline & & $"$ & - & . & . & - & 3 & -3.9326 & $5 \cdot 1551$ \\
\hline & & $"$ & - & . & • & $\cdot$ & 2 & -3.8721 & $7 \cdot 4966$ \\
\hline & & & & & & & & $-6 \cdot 5366$ & $30 \cdot 295^{8}$ \\
\hline \multicolumn{10}{|c|}{ Medium mated to Negative } \\
\hline With Nega & tive c & hildren & & . & . & & & $+32 \cdot 857 \mathrm{l}$ & $46 \cdot 93^{8} 7$ \\
\hline \multirow{6}{*}{$\begin{array}{l}\text { Without } \\
\text { Negative } \\
\text { children }\end{array}$} & I $\mathrm{cl}$ & fild & & . & . & . & 8 & $-6 \cdot 153^{8}$ & $4 \cdot 7337$ \\
\hline & & iildren & & . & . & . & 8 & $-12 \cdot 6316$ & 19.9447 \\
\hline & 3 & ", & $\cdot$ & . & & - & 1 & $-2 \cdot 25^{81}$ & $5.099^{\circ}$ \\
\hline & 5 & ", & - & - & . & · & 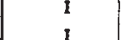 & $\begin{array}{l}-3.0097 \\
-3.2003\end{array}$ & $\begin{array}{r}9 \cdot 0583 \\
10 \cdot 8261\end{array}$ \\
\hline & 10 & ", & : & : & : & : & 1 & $\begin{array}{l}-3 \cdot 2903 \\
-3 \cdot 3225\end{array}$ & $\begin{array}{l}10.8201 \\
11.0390\end{array}$ \\
\hline & & & & & & & & $+2 \cdot 1911$ & $107 \cdot 6395$ \\
\hline
\end{tabular}

Without being wholly exogenic the remaining variation in strength of reaction might be due partly to genes of small effect acting as cumulative factors, or to multiple alleles at the $P$ locus. In the latter case there might be, for example, only two such positive alleles, or equally there might be very many with various grades of strength. Whichever of these views may be favoured, the existence of considerable non-genetic influence must be admitted, and this consideration should prevent any tendency to identify arbitrary, though striking, phenotypic grades with genetic entities. 
At the present stage I suggest that we can express our knowledge of the variability of reactive strength in heterozygotes and homozygotes in the accompanying figure, in which the homozygotes are given just one half of the variance of the heterozygotes, as would be the case if there were a number of allelic positive genes interacting without dominance in respect of strength of reaction, and in such a way that the difference in titre between two homozygotes was the same as that between the corresponding heterozygotes. Whatever may be the interpretation, however, the diagram will serve to illustrate
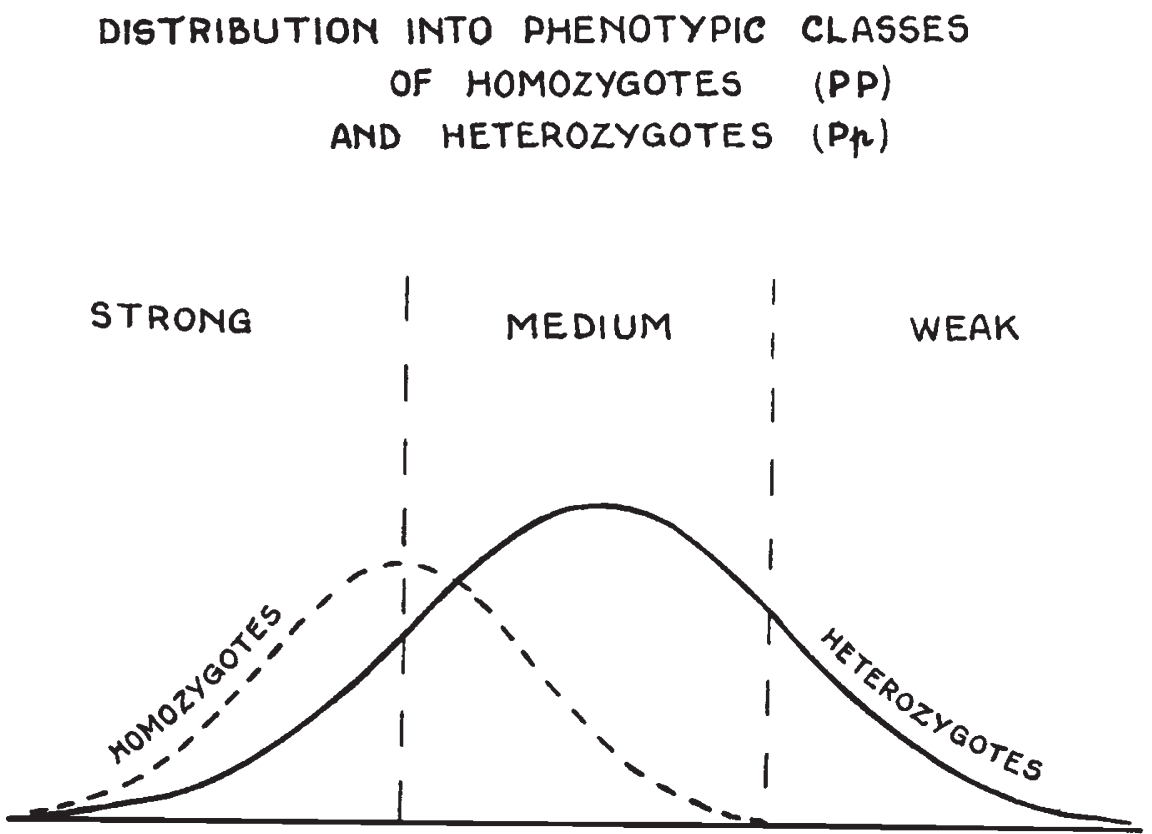

the variability of the two genotypes in relation to the boundaries dividing Strong from Medium, and Medium from Weak, the considerable overlap between their ranges, and the improbability, in view of this variability, of any distinct bimodality or multimodality being recognisable.

An important fact antagonistic to the existence of multiple alleles is the failure of absorption to indicate any qualitative difference between Strong and Weak reactors. This is in contrast to such cases as $A_{1}$ and $A_{2}$, or to the quasi-alleles of the Rhesus system.

\section{SUMMARY}

An analysis of Henningsen's family data, in which parents are classified as Strong, Medium and Weak reactors to anti- $P$ serum shows that these three phenotypic classes contain very unequal proportions of heterozygotes. 
Subject to errors of random sampling, the proportions are estimated to be

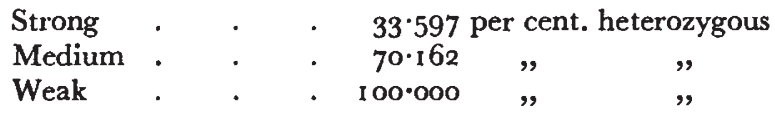

The total number of homozygotes estimated in this way, 123.9 , agrees closely with the number $122 \cdot 6$, estimated from the proportion of Negative parents.

Of the total number enumerated it appears that the homozygotes are about equally divided between the Strong and Medium phenotypes; while of the heterozygotes about 14 per cent. are Strong, 67 per cent. Medium, and 19 per cent. Weak (see figure).

Homozygosity is therefore a well-established cause of the variation of reactive strength. As to the residual causes, it would appear premature yet to infer even that these are of genetic origin, still less that they can be ascribed to a series of recognisable alleles at the $P$ locus.

\section{REFERENCES}

LANDSTEINER, K., AND LEVINE, P. 1927. Further observations on individual differences of human blood. Proc. Soc. Exp. Biol. N.Y., 24, 941-942.

Henningsen, K. 1949. Investigations on the blood factor P. Acta Path. Scand., $26,639-654$.

RAGE, R. R., AND SANGer, R. 1950. Blood Groups in Man. Blackwell, Oxford. 